\title{
Operários chineses em Moçambique. o engajamento de trabalhadores sob contrato no Império português (1857-1859)1
}

\author{
Chinese Workers in Mozambique. The Engagement of \\ Indentured Laborers in the Portuguese Empire (1857-1859)
}

Paulo Cesar Gonçalves*

\section{Resumo}

No final da década de 1850, Lisboa concebeu o emprego de trabalhadores chineses, emigrados de Macau, em serviços considerados especializados (pedreiros, ferreiros, carpinteiros, cobreiros e picadores de pedra), na província de Moçambique, pelo sistema de trabalho sob contrato. Mesmo sem consultar nenhuma autoridade daquelas localidades sobre sua conveniência, a iniciativa produziu uma série de documentos, que transitou de forma vertical entre a metrópole e as colônias. Essa documentação permite identificar um movimento pioneiro de trabalhadores sob contrato dentro dos limites do império português, na esteira do crescente fluxo desse tipo de mão de obra (sobretudo de chineses e indianos) nos mundos Índico e Atlântico. Por outro lado, a documentada disputa entre esses trabalhadores e o governo de Moçambique, sobre a execução e a remuneração dos serviços, também possibilita identificar a agência dos chineses recrutados na defesa de seus direitos registrados em contrato.

Palavras-chave: Trabalho sob contrato; Emigração chinesa; Império português.

\section{Abstract}

At the end of the 1850s, Lisbon conceived the employment of Chinese workers, emigrants from Macau, in services considered specialized (bricklayers, blacksmiths, carpenters, copper workers and stone chippers), in the province of Mozambique, by the system of indentured labor. Even without consulting any authority in those localities about its convenience, the initiative produced a series of documents, which transited vertically between the metropolis and the colonies. This documentation makes it possible to identify a pioneering movement of indentured labor within the limits of the Portuguese empire, in the wake of the growing flow of this type of labor (especially of Chinese and Indian men) in the Indian and Atlantic worlds. Moreover, the documented dispute between these workers and the Mozambican government over the performance and remuneration of services also makes it possible to identify the agency of the Chinese recruits in defending their contractual rights.

Keywords: Indentured labor; Chinese emigration; Portuguese Empire.

\footnotetext{
* Universidade Estadual Paulista (UNESP), Assis, SP, Brasil. pc.goncalves@unesp.br <https://orcid. org/0000-0003-3122-0690>
} 


\section{INTRODUÇÃO}

A migração de trabalhadores sob contrato, amplamente identificada com a figura do coolie ${ }^{2}$, constituiu-se em um dos maiores deslocamentos de mão de obra em todo o mundo após o fim do tráfico de escravizados (1807) e a abolição da escravidão (1833) no império britânico (Emmer, 1997). Assim como o escravismo e outras formas de trabalho forçado, o trabalho sob contrato foi reflexo das desigualdades globais e de estados humanos de exceção que tiveram como consequência a prevalência de relações de poder hierárquicas, bem como vários tipos de exploração, restrição de direitos e exclusão racial (Tappe; Lindner, 2016, p. 11) - características que nem mesmo a relação jurídica do "contrato", tão cara ao liberalismo, conseguiu disfarçar, como contraponto ao sistema escravista.

Formas de trabalho forçado, ou trabalho sob contrato, eram - e são - referidas, muitas vezes, como situações de trabalho com entrada voluntária. No entanto, na prática, os limites entre a entrada coagida e a voluntária são nebulosos. Tappe e Lindner (2016, p. 12) observam a necessidade de se investigar a tensão entre o alegado ingresso "voluntário" no contrato e as reais condições sociais, econômicas e políticas que geraram o vínculo forçado e a falta de capacidade de saída do contrato. Engajados e trabalhadores contratados geralmente concordam com os termos iniciais de seu contrato, mas não são capazes de terminar ou alterar a duração do mesmo após seu início. Invariavelmente, formas de coerção, como pobreza, dívida ou prisão iminente, são necessárias para levar indivíduos a concordar com esse tipo de contrato.

Os contratos frequentemente vinculavam os trabalhadores durante vários anos a determinados locais, com consideráveis restrições ao rompimento do acordo, à liberdade e à mobilidade, porque envolviam endividamento com transporte e sustento, baixos salários e coerção física. Esses contratos, assim como as dívidas dos trabalhadores, também eram objetos de compra e venda. Como observa Zeuske (2016, p. 40), se legalmente era possível vender os contratos dos coolies e não seus corpos, na realidade, ao menos nas áreas onde imperava o sistema escravista, esses trabalhadores eram tratados da mesma forma que os escravizados.

A origem do sistema moderno de trabalho sob contrato migrante data de meados da década de 1820, quando as primeiras tentativas de empregar trabalhadores chineses e indianos nas Ilhas Maurício e Reunião foram malsucedi- 
das. As Ilhas Maurício são reconhecidas como o teste crucial para o uso do trabalho sob contrato nas plantations coloniais após o final da escravidão no império britânico, com a chegada, em 2 de novembro de 1834, de 75 trabalhadores indianos contratados (Allen, 2012, pp. 2-3). A partir de então, trabalhadores asiáticos, principalmente da Índia e da China, geralmente abordados como coolies, foram levados a ambientes coloniais para trabalhar em plantações e minas espalhadas pelo globo, com base no sistema de trabalho sob contrato. Ingleses, americanos, franceses, espanhóis e portugueses estiveram todos fortemente envolvidos na exportação de mão de obra asiática.

Os coolies transformaram-se em outra forma de trabalho descartável; presos em uma interação precária entre a segurança e a exploração do contrato, a dívida e a oportunidade econômica, com o objetivo de satisfazerem as necessidades dos interesses econômicos coloniais, nas áreas de plantações ou de mineração. Eles vicejaram no momento em que os grandes proprietários de terras se recusavam, ou não eram capazes de lidar com o trabalho livre, e exigiam trabalhadores “confiáveis” e baratos após a abolição (Tappe; Lindner, 2016, p. 12).

O trabalho sob contrato tornou-se não apenas fundamental na economia colonial, mas também meio de controle e disciplina, tão caros ao sistema escravista. Sua relevância pode explicar seu alcance global, bem como suas especificidades locais, e mesmo sua coexistência com o trabalho escravo em determinadas áreas, como nos impérios espanhol e português (Scott, 1991; Clarence-Smith, 1985). Tal relevância explica, ainda, a forte demanda por esse tipo de mão de obra - cujos bolsões de origem eram as áreas periféricas do capitalismo -, e, sobretudo, evidencia os limites do liberalismo sob o manto do colonialismo (Young, 2015), ao interrogar a suposta liberdade entre as partes perante o contrato de trabalho.

Introduzido nas colônias do Índico, o trabalho sob contrato chegou às plantations das colônias britânicas e francesas do Caribe após a abolição da escravidão. Neste caso, os antigos contratos de trabalho com europeus (Williams, 1975) ressurgiram no século XIX - então, com imigrantes não brancos provindos de espaços periféricos -, como resposta tanto ao fim da escravidão em algumas áreas específicas, quanto ao crescente aumento do comércio de commodities, à expansão das terras cultivadas - em sintonia com a intensificação dos investimentos capitalistas nas colônias (Northrup, 1995; Tomich, 2012) - e às con- 
dições particulares de demanda por uma mão de obra disciplinada e barata em locais que, na ausência do escravo, não conseguiam atrair trabalhadores livres.

Northrup (1995, pp. 156-161) calcula que pouco mais de dois milhões de imigrantes deslocaram-se sob o regime do trabalho sob contrato, entre $1831 \mathrm{e}$ 1920: 927 mil tiveram como destino as Américas, tendo o Caribe britânico recebido os maiores contingentes; enquanto 560 mil dirigiram-se às colônias tropicais do Índico - Ilhas Maurício e Reunião. Quanto à demografia do fluxo, os homens solteiros compunham a esmagadora maioria e os principais fornecedores dessa força de trabalho. Em termos absolutos, eram oriundos dos territórios indiano e chinês. Da Índia emigraram 1,3 milhão de indivíduos, preferencialmente para o Caribe, as Ilhas Maurício e a Reunião; já da China emigraram 386 mil indivíduos, sobretudo para Cuba e Peru.

Territórios do Império português também se constituíram em fornecedores desse tipo de força de trabalho, como é o caso das possessões na África - Angola e Moçambique -, as quais reeditaram o papel histórico de reserva de população a ser escravizada e traficada para as economias coloniais dos trópicos (Chaillou-Atrous, 2016). Com relação a Macau, enclave português em território chinês, a emigração sob contrato, inerente aos chamados coolies, ancorou-se no trabalho forçado, historicamente constituído no mundo Índico, que divergia da noção ocidental moderna de escravidão (Zeuske, 2018). Por outro lado, o governo português também se preocupou em alocar esses trabalhadores dentro das fronteiras do império, como fica claro, de forma prática, na massiva utilização de trabalhadores da Angola e na breve experiência de coolies chineses nas plantações de cacau em São Thomé e Príncipe (Nascimento, 2004), além das tentativas de colonização de áreas específicas. Nesse sentido, não faltaram leis, decretos e portarias sobre o trabalho da população autóctone - denominada "indígena" -, que associavam a obrigação do trabalho à “missão civilizadora” (Jerónimo, 2010).

Para Portugal, a experiência da emigração de chineses contratados já se fazia sentir desde meados da década de 1840: das centenas, nos primeiros anos, atingiu a casa dos milhares a partir de 1850 até o início da década de 1870, quando foi proibida pelo governo de Lisboa. Os registros oficiais testemunham a preocupação da metrópole portuguesa com o crescente fluxo de saída de chineses, não apenas pelo porto de Macau. Dados estatísticos compilados por Andrade Corvo, então ministro da Marinha e do Ultramar, revelam que, entre 
1845 e 1852, pouco mais de 30 mil indivíduos abandonaram a terra natal pelos portos de Amoy, Wampu, Caming, Macau e Hong-Kong, para se dirigirem a diversos destinos: Havana, Demerara, Ilha Bourbon (Reunião), Austrália, Ilhas Sandwich (Havaí), Filipinas, Califórnia, Peru. O ministro também assinalou a existência dos primeiros contratos de engajamento de agentes ingleses em Amoy, para a remessa de oito mil coolies para Havana e dois mil para Demerara, além da relação direta entre o crescimento do fluxo e os abusos cometidos contra esses trabalhadores emigrantes. Somente por Macau, entre 1856 e 1873, emigraram mais de 143 mil chineses: 73 mil para Cuba e 67 mil para o Peru. Segundo Corvo (1874, pp. 3, 5 e 71), "o governo da colonia, reconhecendo a importancia d'este lucrativo commercio”, buscou controlá-lo.

Preocupação que também se refletiu em um conjunto de leis que, de alguma forma, tentaram tutelar a emigração, de acordo com os interesses da metrópole, ao mesmo tempo em que procuravam lidar com a pressão dos impérios britânico e chinês, contrários à saída de trabalhadores através dos contratos de engajamento. Em 1861, Antonio Feliciano Marques Pereira, então superintendente da emigração chinesa em Macau, elaborou um relatório com o objetivo de apresentar o balanço da saída de chineses, considerados súditos portugueses, pelo seu porto, com especial atenção à legislação da década de 1850 e ao regulamento de 30 de abril de 1860 .

O superintendente dividiu a emigração chinesa em dois períodos. O primeiro, durante a década de 1840, fora marcado pelo voluntarismo, que tinha por destinos principais o Arquipélago Índico, a Malásia, a Polinésia, a Oceania central, Cuba e as minas da Nova Califórnia. Já no segundo, a emigração fora promovida por contratos de engajamento para Cuba, Peru, Ilhas Mascarenhas e Ilha Reunião. Pereira também destacou a presença de engajadores importantes, como os franceses Guillon e Durand e o macauense José Vicente Jorge. O crescimento do número de "estabelecimentos d'emigração", nos quais os emigrantes aguardavam o dia do embarque, era, aliás, um sintoma do aumento do fluxo. No relatório, o superintendente da emigração registrou oito barracões na cidade de Macau - como eram conhecidos à época. Em estudo recente, Cong e Seabra (2017, p. 23) assinalam a existência, em 1851, de cinco barracões, número que aumentou para cerca de dez em 1865 e quarenta em 1866. Já em 1873, às vésperas da proibição do tráfico, havia mais de trezentos desses barracões na cidade. 
Vários regulamentos foram citados no relatório, sempre se ressaltando a necessidade de se evitarem os abusos já ocorridos em viagens de navios fretados para o transporte de emigrantes: a portaria de 12 de setembro de 1853, que regulava as condições sanitárias dos depósitos de emigrantes e dos navios, determinava a fiscalização das instalações, dos mantimentos e da "aguada"; a portaria de 10 de novembro de 1855 tinha como maiores preocupações a "voluntariedade" da emigração e os registros dos contratos no Tribunal da Procuratura; o regulamento de 05 de junho de 1856 objetivava controlar a ação dos engajadores de emigrantes e as normas do transporte transoceânico (Pereira, 1861); o regulamento de 30 de abril de 1860 criou os cargos de Superintendente da emigração chinesa e de Intérprete da língua chinesa, bem como definiu as condições dos contratos e ratificou a proibição de portugueses participarem do recrutamento e do transporte de colonos dentro da China; e o anexo de 12 de outubro de 1860 foi responsável por regular minuciosamente as condições dos navios que recebiam emigrantes chineses.

Ciente do crescente volume da emigração, Pereira (1861, p. 19) alertou para a dificuldade de se impedir a saída de chineses, devido aos tratados que a China foi obrigada a assinar após as Guerras do Ópio (1839-1842 e 1856-1860): "Nos tratados feitos em Pekim, em outubro de 1860, expressamente se estipulou (art. IX. do tratado com a França e V. do tratado com a Inglaterra) que os governadores das provincias chinezas nunca pozessem o menor embaraço ao engajamento de trabalhadores emigrantes". Acordos que revelam o interesse das duas potências imperiais no recrutamento de mão de obra para suas colônias.

No relatório, a emigração de chineses por Macau, entre 1856 e 1860, foi comparada com a de Hong Kong, então colônia britânica, por meio de duas tabelas. Nas saídas por Hong Kong, mais volumosas, predominou o destino australiano, seguido por São Francisco (EUA), Havana e Singapura. Nas saídas por Macau, predominou o destino americano, especialmente para Havana, seguida timidamente por Callao de Lima, enquanto apenas algumas centenas de emigrantes tiveram como destino o Índico. Apesar de inúmeros regulamentos para se tentar tutelar a contratação e a saída de trabalhadores, as péssimas condições das viagens, a comparação com o tráfico de escravizados e a máxima exploração do trabalho nas áreas de destino levaram o governo britânico a proibir, em 1870, a emigração contratada de Hong Kong para qualquer local fora dos domínios do império. Pressionado, Portugal seguiria o mesmo caminho com relação a Macau, em janeiro de 1874. 
Tabela 1

\begin{tabular}{|c|c|c|c|c|c|c|}
\hline \multicolumn{7}{|c|}{ Mappa da Emigração Chineza em Macau, desde 1856 até o fim d'abril de 1860} \\
\hline \multirow{2}{*}{$\begin{array}{l}\text { Paises para onde } \\
\text { os emigrados se }\end{array}$} & \multicolumn{5}{|c|}{ Annos } & \multirow{2}{*}{$\begin{array}{l}\text { Numero total dos } \\
\text { emigrados } \\
\text { nos } 4 \text { annos } \\
\text { e } 4 \text { mezes }\end{array}$} \\
\hline & 1856 & 1857 & 1858 & 1859 & $\begin{array}{c}1860 \text { até } \\
30 \text { d'abril }\end{array}$ & \\
\hline Java & & & 5 & 418 & 77 & 500 \\
\hline Havana & 2.253 & 6.753 & 8.296 & 7.695 & 3.015 & 28.012 \\
\hline Havana, via Hongkong & & & 617 & & & 617 \\
\hline Calháo de Lima & & 450 & 300 & 321 & 542 & 1.613 \\
\hline Demerara, via Hongkong & & & 300 & 460 & & 760 \\
\hline Australia & 240 & & & & & 240 \\
\hline Surinam & & & 500 & & & 500 \\
\hline Pinang & & 150 & & 5 & & 155 \\
\hline Singapura & & & 16 & 25 & & 41 \\
\hline Moçambique & & 30 & & & & 30 \\
\hline Manilha & & & & 45 & & 45 \\
\hline $\begin{array}{l}\text { Somma dos emigrados } \\
\text { em cada anno }\end{array}$ & 2.493 & 7.383 & 10.034 & 8.969 & 3.634 & 32.513 \\
\hline
\end{tabular}

Fonte: Pereira, 1861, p. 28.

Tabela 2

\begin{tabular}{|c|c|c|c|c|c|c|c|c|c|c|c|}
\hline \multicolumn{12}{|c|}{ Mappa da Emigração Chineza em Hongkong, durante os annos 1856, 57 e 58} \\
\hline \multirow{4}{*}{ Destino } & \multicolumn{10}{|c|}{ Annos } & \multirow{4}{*}{$\begin{array}{c}\text { Total } \\
\text { geral } \\
\text { nos } \\
3 \\
\text { annos }\end{array}$} \\
\hline & \multicolumn{4}{|c|}{1856} & \multicolumn{4}{|c|}{1857} & \multirow{2}{*}{\multicolumn{2}{|c|}{$\begin{array}{c}1858 \\
\text { Adultos }\end{array}$}} & \\
\hline & \multicolumn{2}{|c|}{ Adultos } & \multicolumn{2}{|c|}{ Creanças } & \multicolumn{2}{|c|}{ Adultos } & \multicolumn{2}{|c|}{ Creanças } & & & \\
\hline & 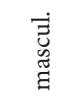 & 苞 & 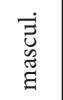 & 惡 & $\begin{array}{l}\dot{\vec{z}} \\
\text { ̋ँ } \\
\text { घ̆ }\end{array}$ & 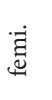 & 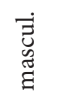 & 苞 & 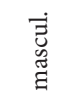 & 莺 & \\
\hline $\begin{array}{l}\text { Guinchen Bay, } \\
\text { Adelaide, Porto } \\
\text { Felipe, Melbourne } \\
\text { e Sidney }\end{array}$ & 7.515 & 1 & 86 & & 17.721 & 1 & & & 8.867 & & 34.191 \\
\hline S. Francisco & 4.843 & 24 & & & 5.273 & 512 & 11 & 7 & 4.803 & 186 & 15.659 \\
\hline Havana & 1.203 & & & & 2.126 & & & & 1.662 & & 4.991 \\
\hline Demerara & & & & & & & & & 292 & & 292 \\
\hline Singapura & 779 & 4 & 10 & 1 & 329 & & & & & & 1.123 \\
\hline $\begin{array}{l}\text { Somma dos } \\
\text { emigrados } \\
\text { em cada anno }\end{array}$ & 14.340 & 29 & 96 & 1 & 25.449 & 513 & 11 & 7 & 15.624 & 186 & 56.256 \\
\hline
\end{tabular}

Fonte: Pereira, 1861, p. 28. 
Cabe destacar-se, na primeira tabela, o registro de trinta emigrantes deslocados para Moçambique em 1857. Esses operários chineses, recrutados por ordem da metrópole para trabalharem em Moçambique, são o objeto deste artigo, representando, como se tentará demonstrar, um exemplo dos ensaios iniciais, por parte da Coroa portuguesa, no intuito de aproveitar a força de trabalho migrante dentro das fronteiras do império, na esteira da experiência da emigração de chineses contratados para várias partes do globo.

Tendo por base o corpus documental localizado no Arquivo Histórico Ultramarino, assim como relatórios oficiais, legislação régia e portarias publicadas nos boletins oficiais coloniais, este artigo também tem como objetivo analisar a percepção contemporânea das relações de trabalho, fragilmente assentadas em contratos, tanto por parte da primeira leva, formada por esse pequeno grupo de emigrantes chineses, como pelo governo da colônia de Moçambique, onde ainda preponderava o trabalho escravo.

No contexto histórico da condenação do tráfico negreiro e da cada vez mais iminente abolição da escravidão, o trabalho sob contrato parecia apresentar-se como caminho natural, em nome da "missão civilizadora" e da "moderna" exploração econômica do império colonial português. Afinal, as relações bilaterais, estabelecidas em contratos, ajustavam-se ao liberalismo e à ideia de que todos, em especial as populações coloniais, deveriam trabalhar. Por outro lado, os registros em documentos da contenda entre os trabalhadores chineses e o governo de Moçambique, sobre a execução e a remuneração dos serviços, possibilitam identificar-se a agência desses engajados na defesa de seus direitos estabelecidos em contrato.

\section{O engajamento em Macau}

Em ofício datado de 27 de fevereiro de 1858, João Tavares de Almeida, então Governador Geral da Província de Moçambique, informava à Secretaria de Estado dos Negócios da Marinha e do Ultramar sobre a chegada da barca portuguesa Adamastor, no dia 19 do mesmo mês, trazendo trinta "colonos Chinas" embarcados no porto de Macau, que foram recrutados e contratados para trabalhar em diferentes ofícios definidos em Portaria Régia publicada em 27 de fevereiro de 1857 (Almeida, 1858a). Junto ao ofício, porém, constava uma relação nominal com apenas 29 emigrantes chineses, e suas respectivas 
profissões - onze pedreiros ou cabouqueiros, oito carpinteiros, quatro cobreiros, quatro ferreiros e dois picadores de pedras -, sem nenhuma explicação sobre a ausência de um trabalhador (Guimarães, 1858b). Cabe observar-se que, na documentação compulsada, ora são mencionados 30 operários, ora 29, o que impossibilitou o estabelecimento, com toda a certeza, de quantos se tratavam. Adotou-se o número de 29 operários, porque são as assinaturas que constam nos requerimentos elaborados pelos próprios chineses.

Segundo a referida Portaria Régia, assinada pelo Visconde de Sá da Bandeira, a ordem era para o governador de Macau engajar de 40 a 50 operários chineses, conforme as "mesmas condições com que costumam contratar-se para o Brazil ou para a ilha Mauricia”, sendo práticos nos seguintes ofícios: "carpinteiro de construcções navaes, dito de obra branca, serrador, serralheiro, ferreiro, caldeireiro, cabouqueiro e funileiro ou latoeiro". As despesas de transporte, assim como aquelas adiantadas em Macau, seriam pagas pelo cofre da província de Moçambique (Portaria de 27/02/1857).

As despesas, remetidas por meio de ofício do governador de Macau, Isidoro Francisco Guimarães, ao de Moçambique, referiam-se ao adiantamento de 30 patacas a cada operário chinês, à importância paga pelo frete da lorcha que os transportou do continente para o navio Adamastor (20 patacas) e às despesas com alimentação e hospedagem enquanto aguardavam o dia do embarque (52 patacas e 25 avos). Junto ao ofício, uma relação com as despesas de "comedoria dos colonos chinas" permite identificar-se a dinâmica geral do processo de recrutamento, que consistia em trazer os trabalhadores para um determinado local - provavelmente um barracão -, onde ficavam hospedados até que se conseguisse reunir a quantidade necessária de engajados a serem embarcados no respectivo navio. Neste caso, os primeiros seis trabalhadores chegaram no dia 6 de novembro de 1857, e os últimos oito, em 12 de dezembro, mas todos tiveram que aguardar mais quatro dias até serem levados à embarcação (Guimarães, 1858a).

No mesmo ofício, alertava o governador que "talvez o Capitão da Barca ahi alegue que fes a arranjo para levar 50 Chinas; não sei que arranjo fes, mas sei que logo que chegou lhe informei que não levaria mais de 40" (Guimarães, 1858c). A observação de Guimarães, além de prevenir qualquer abuso por parte do capitão, parece refletir uma prática comum entre os comandantes de embarcações que transportavam os chamados coolies, endividados com o valor da passagem. 
Dessa forma, a dívida era resgatada nos portos de destino, onde algum interessado poderia quitá-la junto ao capitão, colocando o trabalhador endividado à sua disposição por tempo indeterminado, na medida em que ele só tinha a alternativa da prestação de serviços para o pagamento do débito.

Almeida, ao relatar a chegada dos referidos "colonos engajados por excessivo preço", não se furtou de manifestar sua contrariedade com a empreitada metropolitana, devido ao "grave e onerozo encargo a esta Provincia, elevando a sua despeza a mais quatrocentos mil reis mensaes, sem que tal despeza venha a tirar utilidade correspondente, [haja visto] que de todos os officios havião na Provincia, e dos quaes se obtinha em soffrivel trabalho por muito menor preço", ao passo que, sendo "de maior necessidade obter Carpinteiros de Navio - foi d'este officio, infelizmente, nenhum se poude engajar". A preocupação do governador era com o desenvolvimento da agricultura, setor que mereceria maior atenção quanto à necessidade de braços: "Parece-me que seria muito maior vantagem, se houvessem sido mandados individuos, que se empregassem na agricultura" (Almeida, 1858a).

O alegado alto custo da contratação, "a falta de trabalhos proprios dos seus officios para serem ocupados e a difficuldade em os entender, ou fazer-lhes comprehender o que d'elles se exige", levaram o governador a pedir autorização à Lisboa para dividi-los pelos diferentes distritos da província, onde poderiam ser empregados, "talvez com mais alguma vantagem para o serviço do que n'esta Capital”. Para aliviar o encargo da Fazenda, Almeida aventou a hipótese de procurar particulares interessados em "tomar alguns d'esses operarios, com as condições dos seus contractos”, mas alertava que certamente haveria "muita difficuldade pelo excessivo preço mensal do engajamento em relação com que vencem os artistas indigenas dos respectivos officios" (Almeida, 1858a). A autorização foi dada em portaria de 26 de julho de 1858, que também permitiu ao governador de Moçambique solicitar, diretamente ao governador de Macau, o recrutamento de indivíduos para a agricultura (Almeida, 1858b). ${ }^{3}$

Junto a mesmo ofício, Almeida remeteu documentos enviados pelo governador de Macau, sobre a contratação dos operários chineses. Um deles, datado de 10 de dezembro de 1857, descreve as condições e as dificuldades encontradas para o recrutamento. Apesar das "ordens da Metrópole para engajar até cincoenta operários”, Guimarães observou que só foi possível conse- 
guir 30 trabalhadores, devido ao "incremento do commercio e a demanda por emprego para homem de officio, que fizeram subir os preços dos jornaes extraordinariamente a ponto d'alguns me pedirem quarenta patacas mensais para irem para Moçambique, além de deixar aqui uma mizada para suas familias pago pelo Governo" (Almeida, 1858c).

Guimarães ainda informou que não conseguiu arranjar "Carpinteiros de navio" e que os 30 operários chineses - em sua maior parte de fora de Macau - receberam um "adiantamento n'esta Cidade de trinta patacas para serem descontados em Moçambique a uma razão de uma pataca por mez dos seus salarios, levando cada um os instrumentos da sua profissão, bem como o seu contrato", cujo modelo estava em anexo, acompanhado da relação com nomes e profissão de cada um dos operários (Almeida, 1858d).

Apesar de longa, a reprodução do modelo de contrato é bastante elucidativa quanto às condições de trabalho, remuneração e penalidades características do engajamento de trabalhadores naquele momento:

natural da Villa de na Provincia de na China, de idade de __ annos, declaro que tenho concordado com o Governo de Macáu a embarcar para Moçambique a bordo do navio Portuguez Adamastor, obrigando-me logo que chegue a meu destino, a empregar-me alli ás ordens do Governo d'aquella Provincia para trabalhar pelo meo officio de durante as horas distribuidas no trabalho, ou como possa ser mais conveniente ao dito Governo, dando cumprimento ao meo trabalho por dez patacas de soldo mensal, e uma ração diaria de oito onças de vaca e meia libra de outros sustentos alimentares, assistencia medica, e remedios, recebendo por anno duas mudas de roupa, um cobertor, e uma camisa de lã; concordando-se igualmente, que em occasião de doença, excedendo ella a quinze dias, o meu salario será suspenso até que eu volte ao trabalho, continuando porem a ser tratado por conta do mesmo Governo.

Cumprindo estas obrigações por espaço de oito anos continuados, que está fixado para termo d'este contracto, durante o qual não me será permittido largar a colônia, nem negar os meus serviços ao mencionado Governo; findo este praso me dará plena liberdade para obrar a que melhor me convir. A minha passagem e sustento a bordo do navio será por conta do Governo Portuguez, recebendo aqui adiantado por conta do Governo de Macau a quantia de trinta patacas, para os meus arranjos de viagem, como, compra de roupa para uso e instrumentos proprios do meu officio; com a condição de que a mencionada quantia me seja descontada ali no meu salario a razão de huma pataca por mez, 
até o final embolso; devendo-se entender que por nenhum outro motivo me será deduzida couza alguma do meu salario, o qual principiará a correr vinte e quatro horas depois do meo desembarque na dita colônia.

Macau de de 185 (Almeida, 1858e, grifos do autor).

O primeiro aspecto que chama atenção é o tempo do contrato, ou seja, de oito anos, durante os quais o trabalhador ficaria totalmente à disposição do contratador, sem qualquer direito de negar seus serviços ou mesmo abandonar a província. Além disso, as horas diárias de trabalho não estavam discriminadas, assim como os dias de descanso. O segundo aspecto refere-se à remuneração e à manutenção: cada operário chinês teria direito a um salário mensal de dez patacas, a ração diária, a assistência médica, a vestuário limitado, mas, em caso de afastamento por mais de quinze dias por motivo de doença, o salário seria suspenso até o retorno ao serviço. Por último, as despesas pré-contratuais: enquanto os custos do transporte ficavam a cargo do Estado, o adiantamento de 30 patacas recebido em Macau seria descontado mensalmente em uma pataca.

É importante observar-se que, como apontou a portaria de 27 de fevereiro de 1857, o contrato não fugia do padrão utilizado no engajamento de trabalhadores para as colônias britânicas e francesas no Índico e no Caribe. No apêndice ao relatório do superintendente da emigração chinesa constava o modelo geral de contrato celebrado entre os agentes da emigração e os emigrantes, autorizado pelo regulamento de 30 de abril de 1860. Nele, o engajado comprometia-se a trabalhar sob as ordens do contratador ou de qualquer pessoa a quem o contrato fosse repassado. O tempo de serviço permanecia de oito anos, com jornada de trabalho de até 12 horas - mas o domingo era considerado dia de descanso -, salário mensal de quatro pesos fortes e alimentação diária. Assegurava-se ainda a liberdade do trabalhador após o final do contrato, que não poderia ser prorrogado mesmo em caso de dívida. Uma observação ao final do contrato revela a condição subalterna dos coolies que se dirigiam a Cuba e ao Peru: "Declaro que me conformo com o salario estipulado, ainda que me consta que é muito maior o que recebem ali os outros trabalhadores", porque deveriam ser consideradas as vantagens oferecidas no contrato e as despesas da viagem pagas pelo patrão (Pereira, 1861, p. 19).

No caso do Brasil, a portaria de 27 de fevereiro de 1857 provavelmente fazia referência ao contrato celebrado no ano de 1855, em Londres, entre o 
governo imperial e a casa Sampson \& Tappan, para a importação de dois mil chineses, cujo tímido resultado foi a chegada ao Rio de Janeiro de apenas 367 trabalhadores, em 1856. No contrato de engajamento de um trabalhador de 30 anos chamado Owlin, relacionado a esse acordo, é possível verificar-se o tempo de serviço (cinco anos), o adiantamento de 15 patacas e as nove horas diárias de trabalho, porém, a remuneração não estava definida - por outro lado, o patrão obrigava-se a fornecer peças de vestuário, alimentação e assistência médica em caso de doença (Elias, 1970, pp. 99-100).

\section{A BREVE EXPERIÊNCIA CHINESA EM MoÇAMBIQUe}

Os operários chineses não enfrentaram apenas as duras condições resultantes do contrato - supostamente assinado por sua livre vontade -, as diferenças culturais e as dificuldades de comunicação. A percepção negativa, por parte dos administradores da província, dos proprietários, dos comerciantes e dos juízes, com relação ao comportamento dos trabalhadores, era obstáculo intransponível, sobretudo no que dizia respeito ao trabalho por eles realizado.

Quatro meses após a chegada dos chineses, Almeida já considerava a experiência um fracasso. O governador alegava que os operários contratados em Macau não desempenhavam como deviam os trabalhos dos ofícios a que diziam pertencer, e que vinha expresso em cada um dos seus contratos, "resultando em grande prejuízo aos cofres da Fazenda, que tem por sua parte religiosamente cumprido as condicções dos referidos contractos, pagando aos sobreditos Chinas um salario disproporcionado com o produto que de seus trabalhos resulta" (Almeida, 1858f).

Colocando em dúvida as qualificações técnicas dos operários, o governador achou necessário averiguar "a aptidão de cada um dos referidos Chinas, destinguindo os que estão no caso de serem considerados e empregados como officiaes do officio que dizem ter, e aquelles que o não estão". Para tanto, afirmando zelar pelas "garantias de justiça e imparcialidade tanto para os individuos de que se trata, como para a Fazenda Publica", determinou a criação "o mais breve possível de uma Commissão composta do Inspector do Arsenal, do das Obras Publicas, dos Proprietarios José Francisco da Piedade Pereira, Rafael de Mendonça, e Vicente Thomás dos Santos”. O objetivo era proceder, "com a assistencia do interprete China, ao exame de que se trata, encarregan- 
do a cada um dos Chinas, que constam da relação junta, um trabalho qualquer pertencente ao seu officio, e em o qual elle possa mostrar que o sabe exercer convenientemente" (Almeida, 1858f).

A Comissão foi instaurada em 5 de julho e, no dia seguinte, reunida no Arsenal da Marinha, realizou o exame de cada um dos operários chineses, com o auxílio de mestres nos ofícios que cada um exercia. Dessa forma, a Comissão, apoiada na opinião dos mestres, declarou se cada um dos operários chineses estava ou não apto para exercer o "officio que diz ter". Todo procedimento, inclusive os resultados dos exames, foram comunicados aos operários através do intérprete. Por fim, em relatório, a Comissão propôs, "tendo em vista os contractos, feitos pelo governo de Macáu, o melhor emprego que a cada um dos referidos examinados se poderá dar" (Almeida, 1858g).

O relatório com os pareceres sobre os operários chineses conforme o ofício exercido é um desfile de estereótipos e julgamentos morais, mesclados com a preocupação em relação à análise técnica.

[...] nenhum dos ditos operarios pedreiros, é artifice completo, e com perfeição para poder emprheender e dirigir qualquer obra d'edificio, ou outra particular [...] duas partes d'elles são apprendizes, que a terça parte dos mais pouco habilitados podem trabalhar conjunctamente com algum Mestre; tal é o desleixo, e omissão d'elles, que até esta data não tem ferramenta precisa da sua arte, não obstante de cada um d'elles receber por adiantamento trinta patacas para seus arranjos e feitura de ferramentas como consta do contracto feito com o Governo de Macáu.

No exame dos sete operarios carpinteiros se encontrou só um que diz ser unicamente entalhador d'obra fina, e declarou perante a Commissão, que não sabia trabalhar na obra groça de madeira; porém o feitio da obra fina feita, e apresentada por elle na estimativa de quatro mil reis, não dá equilibrio a despesa feita pela fazenda com aquelle operario na importancia de sete mil trezentos e vinte reis; sendo dois, dos restantes seis, apenas serradores de madeiras, e os outros quatro operarios, se não preguiçosos, ao menos mais vagarósos.

Dos quatro cobreiros, dois são minimamente morozos na obra, e o seu feitio faz differença no quadruplo da despesa, sendo dos restantes dois, um é simples apprendiz, e outro vindo sob a protecção de outro para ganhar, sendo ignorante do officio, e empregado unicamente em tocar os foles. 
Dos quatro ferreiros, um é soffrivel operario, que pode trabalhar na obra de enchadas e pregos, sendo outro operario tosco e groceiro, os dois restantes, um é malhador de ferro e o outro tocador de ferro (Almeida, 1858g, grifos do autor).

Na conclusão do relatório, a Comissão indicou a "enorme e inutil despeza, que o Cofre da Fazenda fáz com aquelles Chins, denominados operarios", considerou os gastos excessivos - pois "com a metade da despesa a fazer com elles poderá a fazenda alcançar qualquer obra pelos operarios da terra mais perfeitos do que eles" - e, de forma unânime, decidiu "que se devem dár por dissolvidos os contractos" com os chineses por serem "inconvenientes, e prejudiciaes á Fazenda Publica”. Dessa forma, propôs que a Fazenda deveria “dar-lhe[s] o livre transporte e comedorias em qualquer navio, no caso queirão elles regressar para a sua terra", para evitar o prejuízo financeiro maior, na "importancia de quatro contos de reis annuaes". Um ponto, no entanto, chama atenção. Com a quebra do contrato por parte do governo, os operários chineses ficariam ociosos enquanto aguardavam algum navio para voltarem à Macau, o que levou a Comissão a sugerir que, durante o tempo de espera, eles fossem "empregados pelo Governo, em qualquer obra", com remuneração mais baixa do que recebiam pelo contrato original: "os mais habilitados devem vencer duzentos reis diarios, e cem os aprendizes” (Almeida, 1858g).

Essas decisões arbitrárias apresentadas pela Comissão no relatório de 7 de julho, no entanto, foram contestadas pelos operários chineses, através de uma petição coletiva, produzida sete dias depois, com auxílio do mesmo intérprete que participou do exame. Os peticionários aproveitaram ainda para reclamar de certas medidas punitivas consideradas absurdas, por não estarem descritas no contrato. Não faltaram argumentos para refutarem o parecer da Comissão, bem como para explicitarem a agência dos trabalhadores chineses no intuito de defenderem seus direitos, de acordo com o registrado no contrato assinado com o governo de Macau no dia 10 de dezembro de 1857.

Inicialmente, "com toda a submissão e humildade", os operários chineses "abaixo assignados" elencaram as condições e as garantias do contrato: o vencimento de dez patacas mensais, a ração diária, a assistência médica, os remédios e o vestuário. Depois, lembraram que, ao chegarem ao porto de Moçambique, experimentaram a quebra da primeira condição, segundo a qual deveriam ser "abonados do vencimento logo depois de vinte e quatro horas do 
desembarque", o que, segundo eles, ocorreu apenas no dia 24 de fevereiro, causando a perda de três dias de salário (Almeida, 1858h).

O pior, porém, ainda estava por vir no trabalho cotidiano. Segundo o requerimento, "os supplicantes teem sofrido outros discontos arbitrariamente feitos contra o contractado", devido à falta de pontualidade, ao abandono ou à recusa do serviço, enquanto domingos e dias santos não eram abonados. $\mathrm{O}$ argumento fundamental era que os "supplicantes não vierão ajustados para receber o vencimento parcial, e com fracção dos dias domingos e dias Santos, se não o seu salario solido e mensal de des patacas”. Alegavam que só vieram para Moçambique porque o governo de Macau, em consequência da ordem do Governo de Sua Majestade, garantiu que o contrato seria "religiosamente cumprido". No entanto, era prática comum "aquelles descontos arbitrariamente feitos contra o espirito dos seus contractos, em que é tão clara e explicita a clausula, que diz devendo-se entender o contracto, que por nenhum outro motivo sera deduzida cousa alguma do nosso salario" - exceção feita, lembravam, ao desconto por motivo de doença que ultrapassasse quinze dias. Ao final do requerimento, os 29 operários chineses diziam-se "martyres e prejudicados nos seus interesses", e afirmavam que foram obrigados a recorrer à justiça para evitar "descontos arbitrarios que não patentes do contracto, no vencimento mensal dos seus trabalhos, e rações a não ser por motivo de doença excedente á quinze dias, e mandar restituir os descontos injustamente feitos nos vencimentos e rações nos meses decorridos" (Almeida, 1858h).

Três dias depois, em reunião do Conselho do Governo, o governador de Moçambique expôs a situação dos trabalhadores chineses: fez um breve esboço desqualificando o serviço dos operários, destacou "a falta de cumprimento por parte dos mesmos, para com o Governo do contracto a que elles se tinhão voluntariamente sujeitado" e declarou que, em consequência das "repetidas e amiudadas faltas que elles commettião", havia ordenado que, quando não comparecessem no horário do trabalho, abandonassem este antes da hora marcada para finalizá-lo ou se recusassem a fazer o serviço determinado, "lhes fosse abatido esse dia do vencimento". Por fim, o governador apresentou o relatório da Comissão encarregada de examinar a qualidade dos operários e abriu a palavra para os membros do Conselho (Almeida, 1858j).

Um dos conselheiros, identificado no documento apenas como juiz de direito, considerou justas as medidas tomadas "e de que era de opinião que 
nenhum dos operarios se devia dar salario, uma vez que não trabalhassem, salvo caso de doença - marcado no contracto". Outro conselheiro manifestou-se favorável à adoção de medidas repressivas adotadas pelo governador contra "os abusos commettidos pelos operarios Chinas", porque "sendo o contracto propriamente dito bilateral [...], quando qualquer das partes não cumpria áquilo a que se havia comprometido, a outra tinha o direito d'igualmente o não preencher". Como os demais membros do Conselho aceitaram os argumentos apresentados, ficou acordado por unanimidade que "quando os operarios Chinas não trabalhassem, se lhes não devia dar salario” (Almeida, 1858j).

Um mês depois, um novo requerimento dos operários chineses voltava a observar que as condições do contrato impossibilitavam "faser semelhante desconto não tratado, nem convencionado". E, o mais importante, afirmava que era incontestável que os suplicantes, como "Artifices e Operarios de baixo de ajuste vindo de Macáu”, deviam ser "equiparados n'este Porto como Empregados, e Servidores do Governo Portuguez, e não jornaleiros, que vencem diariamente o jornal pelos seus trabalhos, e assim não é de justiça que soffrão os descontos mesquinhos doptados do Governo, tornando-se por isso injusto". Em vista desses fatos, mais uma vez recorriam ao governador para que ele mandasse abonar os descontos já feitos e os proibisse no futuro (Almeida, 1858i).

$\mathrm{Na}$ documentação compulsada existe uma lacuna de quase um ano nas informações sobre os operários chineses. A situação, porém, não deve ter se alterado muito, pois, em 28 de julho de 1859, um novo requerimento, assinado por 20 chineses, não mais contestava o descumprimento de cláusulas do contrato, mas solicitava "humilde e respeitosamente" ao governador "para que fossem transportados por conta do estado para a sua Patria", na galera portuguesa Novo Viajante, que deveria sair de Moçambique com destino ao porto de Macau (Almeida, 1859a).

Em 30 de julho, ao Conselho do Governo, foi apresentado o requerimento dos operários chineses no qual solicitavam o regresso à Macau. A reclamação, por parte do governo, de que os contratos feitos em Macau eram vantajosos para os operários e desfavoráveis à província de Moçambique, apoiava-se na alegada boa vontade "com que aqui foram recebidos, cumprindo-se com pontualidade e com sacrifício todas estas condições durante alguns mezes". Segundo Almeida, o problema, na verdade, residia nos próprios trabalhadores: 
[...] mas a ignorancia e a preguiça destes homens era tam escandalosa - e abuzaram tanto do desejo que havia de os conservar - que foi necessaria subjeital-os a um exame, de que quase todos elles sahiram mal, foi necessario mais pôr cobro ás referidas faltas e abandono do pessimo e pouco trabalho que faziam, subjeitado-os a multas por essas faltas e abusos - mas nada disso produzio efeito sobre estes homens incorrigíveis (Almeida, 1859b).

Recorrendo ao argumento mencionado no ofício que noticiou a chegada dos operários chineses - ou seja, de que a contratação desses trabalhadores era muito dispendiosa -, o governador informou que foi necessário, "em vista do seu pouco e não trabalho", determinar, em Junta da Fazenda, que metade "do vencimento exorbitante que tinham" ficasse em reserva, por que ainda assim "o seu trabalho não podia comprehender nem de leve esse mesmo jornal que lhe ficava". A medida foi tomada para "indemnisar pelo modo possivel a Fazenda, dos adiantamentos de trinta pezos que a cada um dos ditos Chinas se havia feito em Macao".

Pelo relato de Almeida, a reação dos trabalhadores foi imediata:

Alguns delles abandonaram então de todo o trabalho - perdendo a ração e o salario - outros só vinham na vespera do dia em que recebiam as rações e se distribuia o jornal, para a poderem receber. - Foi necessario mandar alguns delles para Quilimane, recusaram-se a fasel-o, que ou haviam de ir todos, ou elles não hiam (Almeida, 1859b).

Em vista do que foi denominado como "especie de revolta", o governador mandou rescindir o contrato, e colocou em prática a proposta de não deixá-los sem trabalhar para evitar deixá-los na "ociosidade". Sob a alegação de que eles não ficassem sem recursos, "se lhes mandou abonar um tostão quando se apresentassem para o trabalho, como operarios nas obras publicas”. Para indignação do governador, "nenhum delles se quiz approveitar deste favor" e "preferiram viver á custa dos seus companheiros, daqueles que ainda por semana vinham um ou outro dia ao trabalho, a trabalharem para ganhar algum meio de viver". Outra tentativa de empregar os trabalhadores chineses sem sucesso foi relatada pelo governador "que lhes tinha offerecido a irem estabelecer-se em Pemba, ou em qualquer outro ponto da Provincia, dando lhes terra e 120 reis diarios por um anno - todos se recusaram" (Almeida, 1859b).

O diagnóstico derradeiro não poderia ser outro por parte do mandatário. 
Se o governo de Moçambique supostamente cumpriu com sua parte estabelecida no "oneroso contrato" a mando da metrópole, o problema estava do outro lado - o dos contratados. Dessa forma, Almeida carregava nas tintas a respeito do "comportamento condenável" dos operários chineses:

[...] se devia approveitar [a vinda da barca Adamastor], para libertar a Provincia de similhante gente, e da execução de taes contractos [...] [e] poder despedir estes individuos tam prejudiciaes á Provincia pelas seus maus costumes - e reprehensivel conducta sendo jogadores ociosos - de que eram prova acharem-se cinco com processo por falsificação e passadores de moeda falsa (Almeida, 1859b).

Em 2 de agosto de 1859, o Governador Geral da Província de Moçambique comunicava ao governo de Macau o regresso de 22 operários chineses com seus respectivos passaportes, porém, sem esquecer de justificar, mais uma vez, o fracasso da empreitada, com base no estereótipo apresentado desde a chegada dos mesmos a Moçambique: "mas os seus máos costumes, vicios, preguiça invecivel, e a ignorancia dos seus officios, em que são menos aptos do que os indigenas cujos salarios andam por um quarto, do que elles deviam ter" (Almeida, 1859c).

Sete dias depois, Almeida, em ofício endereçado ao Secretário de Estado dos Negócios da Marinha e Ultramar, apresentava um breve relatório sobre as razões do rompimento dos contratos e do regresso dos chineses a Macau na galera Viajante. Afinal, o insucesso da experiência ordenada por Sua Majestade merecia alguma explicação. E, mais uma vez, ela não haveria de ser outra senão a da alegada "incapacidade moral" dos chineses para o trabalho e o cumprimento dos contratos, somada ao alto custo da remuneração a que tinham direito: "Pelo meu officio $\mathrm{N}^{\circ}$ 159/1858 informei a V. Exa. [...] do não serviço prestado pelos referidos operarios, os quaes, além de muitos defeitos, não sabiam trabalhar pelos seus officios". Mesmo considerando o contrato oneroso e "altamente lesivo para a Fazenda", o governador afirmava ter tentado manter "aquelles mandriões e empregando os meios para delles haver algum serviço, até que recebesse novas ordens da metrópole” (Almeida, 1859d).

Nesse espaço de tempo, o governador ordenou ao "Inspector das Obras Publicas para que nomeasse 12 daquelles operarios para serem mandados para Quilimane, afim de ficarem á disposição do Governador da Zambezia, e por este serem convenientemente empregados nas differentes obras [...], que lhe 
tinham sido incumbidas". Para a reprovação do mandatário, os chineses "recusaram-se a marchar para onde eram mandados, impondo como condição, que ou haviam de ir todos ou nenhum". Restava, então, ameaçá-los com a rescisão do contrato, a redução dos proventos ao nível da força de trabalho local e a remuneração por jornal:

Em presença desta recusa - ordenei peremptoriamente ao referido Inspector das Obras Publicas, que fisesse saber aos Chinas nomeados, que na conformidade do seu contracto eram obrigados a ir servir aonde lhes fosse indicado; e por consequencia se elles persistiam na recusa lhes mandava considerar como rescindido o contracto. - Assim foram intimados, e o resultado foi negarem-se a sahir de Moçambique - mandei por tanto, como lhes havia feito constar, considerar rescindido o contracto com aquelles 12 Chinas - fazendo-lhes em seguida saber, que seriam de futuro admittidos nas Obras Publicas - não mediante o salario que ate alli lhes era dado - mas sim em relação áquelle por que eram pagos os operarios do paiz (Almeida, 1859d).

Os dezoito restantes, nas palavras do governador, tiveram o seguinte destino: cinco foram presos e "existem em Processos por falsificadores de moeda", três faleceram do "Cholera", e os outros dez continuaram como empregados nas obras, "mas faltando continuadamente, e fazendo pessimo serviço, como meros serventes, pois que para mais não serviam”. Por fim, após o requerimento apresentado pelos trabalhadores chineses solicitando o regresso a Macau, Almeida aproveitou a chegada da galera Viajante e decidiu, em conjunto com o Conselho de Governo, que devia "conceder-se-lhes a sua ida - e ser rescindido o contracto - visto que com tal gente era despeza perdida, aquella que o Estado fazia”, por entender que o "Estado tudo lucrava - ainda mesmo dando-se o caso de que elles devessem á Fazenda - por effeito dos adiantamentos que lhes tinham sido dados em Macáo”. Em síntese, os operários chineses eram dispensáveis, “pois os seus maos habitos e incapacidade para os trabalhos os fasiam mais perniciosos do que uteis ao serviço e á Provincia" (Almeida, 1859d).

As passagens foram concedidas, mas a cobrança foi repassada ao governo de Macau: "solicitei do Governador de Macáo - que fosse satisfeita a importancia do transporte dos Chinas pelo Cofre daquela Provincia - e as razões que motivaram esta requisição". Afinal, lembrava Almeida: "Aquelles individuos ficaram ainda debitados para com a Fazenda, na importancia total de 85\$023 reis". Quantia considerada insignificante em relação "ao grande alivio que ao 
Cofre da Provincia resulta da retirada d'aquelles inuteis individuos que a sobrecarregam com um encargo annual superior a quatro contos de reis" (Almeida, 1859d). Se a conta do recrutamento ordenado pela metrópole portuguesa foi paga pelo governo de Moçambique, a do repatriamento ficaria a cargo de Macau, ao menos é o que pretendia Almeida: "Comunicando que regressão a Macáo vinte e dois dos operarios Chinas, que tinham vindo servir n'esta Provincia por engajamento e solicitando que seja satisfeita ao Commandante do Navio o transporte dos mesmos Chinas" (Almeida, 1859c).

\section{CONSIDERAÇÕES FINAIS}

Menos de dois anos depois de colocada em prática, por ordem de Lisboa, a precária experiência com os operários chineses sob contrato de trabalho em Moçambique estava encerrada. As dificuldades surgiram já no recrutamento em Macau, ligadas à conjuntura favorável da economia local ou mesmo à concorrência dos engajamentos destinados à Havana. As estratégias não diferiam do modus operandi tradicional em território chinês: aliciar trabalhadores, levá-los aos barracões, onde aguardariam o embarque no navio, e fazê-los assinar os contratos de trabalho.

A troca de correspondências entre metrópole e colônias demonstra que a empreitada transoceânica dos operários chineses foi uma decisão monocrática, imposta pela Coroa, sem consultar os dois governos dos territórios ultramarinos envolvidos. O resultado da chegada e dos serviços prestados pelos imigrantes revelou-se infrutífero e breve, como se depreende das queixas e decepções do governador de Moçambique e dos próprios trabalhadores chineses engajados.

Pelo que se verifica nas fontes compulsadas e aqui analisadas, a percepção, por parte do governo colonial de Moçambique, era de que os operários chineses nada tinham a contribuir para a propalada "missão civilizadora" do colonialismo português na África - ao menos naqueles meados de Oitocentos, em que a escravidão ainda era legal no império. Ao que parece, Lisboa, representada pela Secretaria dos Negócios da Marinha e do Ultramar, acreditava nessa missão e ensaiava alguns passos para colocá-la em prática, ao mesmo tempo em que tentava, de alguma forma, articular os interesses de um império tão vasto e diverso quanto disperso. 
Os documentos revelam também a agência dos trabalhadores chineses. Se não foi possível averiguarem-se as condições do recrutamento, principalmente em relação ao livre arbítrio na assinatura dos contratos, vale destacar-se a tentativa de organização do grupo para a defesa de seus direitos e a percepção de que estes encontravam guarida no contrato assinado em Macau, antes do embarque para Moçambique. O resultado não poderia ser outro: as manifestações de contrariedade foram muito mal recebidas pelos representantes do governo de Moçambique e serviram para intensificar ainda mais a visão negativa a respeito dos trabalhadores chineses. Sob a ótica oficial, ou seja, oriunda do lado que detinha maior poder de pressão, o não cumprimento adequado das obrigações estabelecidas no contrato justificava plenamente seu rompimento.

A emigração dos operários chineses transportados gratuitamente pelo Estado foi uma experiência oficial tímida, mas que permite lançar-se luz sobre os propósitos da metrópole portuguesa ao procurar seu espaço dentro do fenômeno migratório de trabalhadores sob contrato, que ganhava contornos cada vez mais nítidos a partir de meados da década de 1830, no Império britânico e, depois, no francês. O esforço configurou uma tentativa pioneira de se ultrapassar a função desempenhada por seus territórios coloniais, como fornecedores de braços para a economia mundial, canalizando ao menos parte desses esforços para o desenvolvimento das próprias províncias ultramarinas.

\section{REFERENNCIAS}

ALLEN, Richard B. European Slave Trading, Abolitionism, and "New Systems of Slavery" in the Indian Ocean. Journal of Multidisciplinary International Studies, Sydney, v. 9, n. 1, 2012.

ALMEIDA, João Tavares de. Ofício No 10, de 27/02/1858, de João Tavares de Almeida, Governador Geral de Moçambique; Cx. 20 - 1858, Moçambique - SEMU - DGU (Arquivo Histórico Ultramarino, AHU). 1858a.

ALMEIDA, João Tavares de. Portaria de 26/07/1858, anexa ao Ofício $\mathrm{N}^{\circ} 10$, de 27/02/1858, de João Tavares de Almeida, Governador Geral de Moçambique; Cx. 20 - 1858, Moçambique - SEMU - DGU (Arquivo Histórico Ultramarino, AHU). $1858 \mathrm{~b}$.

ALMEIDA, João Tavares de. Cópia $\mathrm{N}^{\circ} 1$, anexa ao Ofício $\mathrm{N}^{\circ} 10$, de 27/02/1858, de João Tavares de Almeida, Governador Geral de Moçambique; Cx. 20 - 1858, Moçambique - SEMU - DGU (Arquivo Histórico Ultramarino, AHU). 1858c. 
ALMEIDA, João Tavares de. Cópia $\mathrm{N}^{\circ} 2$, anexa ao Ofício $\mathrm{N}^{\circ} 10$, de 27/02/1858, de João Tavares de Almeida, Governador Geral de Moçambique; Cx. 20 - 1858, Moçambique - SEMU - DGU (Arquivo Histórico Ultramarino, AHU). 1858d.

ALMEIDA, João Tavares de. Cópia $N^{\circ} 3$, anexa ao Ofício $N^{\circ} 10$, de 27/02/1858, de João Tavares de Almeida, Governador Geral de Moçambique; Cx. 20 - 1858, Moçambique - SEMU - DGU (Arquivo Histórico Ultramarino, AHU). 1858e.

ALMEIDA, João Tavares de. Cópia $\mathrm{N}^{\circ} 1$, anexa ao Ofício $\mathrm{N}^{\circ} 159$, de 25/06/1858, de João Tavares de Almeida, Governador Geral de Moçambique; Cx. 22 - 1858, Moçambique - SEMU - DGU (Arquivo Histórico Ultramarino, AHU). $1858 \mathrm{f}$.

ALMEIDA, João Tavares de. Cópia $\mathrm{N}^{\circ} 2$, anexa ao Ofício $\mathrm{N}^{\circ} 159$, de 25/06/1858, de João Tavares de Almeida, Governador Geral de Moçambique; Cx. 22 - 1858, Moçambique - SEMU - DGU (Arquivo Histórico Ultramarino, AHU). 1858g.

ALMEIDA, João Tavares de. Cópia $\mathrm{N}^{\circ} 3$, anexa ao Ofício $\mathrm{N}^{\circ} 159$, de 25/06/1858, de João Tavares de Almeida, Governador Geral de Moçambique; Cx. 22 - 1858, Moçambique - SEMU - DGU (Arquivo Histórico Ultramarino, AHU). 1858h.

ALMEIDA, João Tavares de. Cópia $\mathrm{N}^{\circ} 4$, anexa ao Ofício $\mathrm{N}^{\circ} 159$, de 25/06/1858, de João Tavares de Almeida, Governador Geral de Moçambique; Cx. 22 - 1858, Moçambique - SEMU - DGU (Arquivo Histórico Ultramarino, AHU). 1858i.

ALMEIDA, João Tavares de. Cópia $\mathrm{N}^{\circ} 5$, anexa ao Ofício $\mathrm{N}^{\circ} 159$, de 25/03/1858, de João Tavares de Almeida, Governador Geral de Moçambique; Cx. 22 - 1858, Moçambique - SEMU - DGU (Arquivo Histórico Ultramarino, AHU). 1858j.

ALMEIDA, João Tavares de. Cópia $N^{\circ} 1$, anexa ao Ofício $N^{\circ} 59$, de $09 / 08 / 1858$, de João Tavares de Almeida, Governador Geral de Moçambique; Cx. 23 - 1859, Moçambique - SEMU - DGU (Arquivo Histórico Ultramarino, AHU). 1859a.

ALMEIDA, João Tavares de. Cópia $N^{\circ} 2$, anexa ao Ofício $N^{\circ} 59$, de 09/08/1858, de João Tavares de Almeida, Governador Geral de Moçambique; Cx. 23 - 1859, Moçambique - SEMU - DGU (Arquivo Histórico Ultramarino, AHU). 1859b.

ALMEIDA, João Tavares de. Cópia $N^{\circ} 3$, anexa ao Ofício $N^{\circ}$ 59, de 09/08/1858, de João Tavares de Almeida, Governador Geral de Moçambique; Cx. 23 - 1859, Moçambique - SEMU - DGU (Arquivo Histórico Ultramarino, AHU). 1859c.

ALMEIDA, João Tavares de. Ofício $\mathrm{N}^{\circ}$ 59, de 09/08/1858, de João Tavares de Almeida, Governador Geral de Moçambique; Cx. 23 - 1859, Moçambique - SEMU - DGU (Arquivo Histórico Ultramarino, AHU). 1859d.

BALACHANDRAN, Gopalan. Making Coolies, (Un)Making Workers: "Globalizing” Labour in the Late-19th and Early-20th Centuries. Journal of Historical Sociology, Alberta, v. 24, n. 3, pp. 266-296, 2011.

CHAILLOU-ATROUS, Virginie. La reprise de l'immigration africaine à La Réunion à la fin du XIXème siècle: de la traite déguisée à l'engagement de travail libre. French Colonial History, Michigan: State University Press, v. 16, pp. 27-54, 2016. 
CLARENCE-SMITH, William Gervase. O Terceiro Império português (1825-1975). Lisboa: Teorema, 1985.

CONG, Liu; SEABRA, Leonor Diaz de. O tráfico de Cules através do porto de Macau. Revista de Cultura, Macau, n. 55, pp. 20-41, 2017.

CORVO, Andrade. Relatorio e documentos sobre a Abolição da Emigração de Chinas Contratados em Macau apresentado ás Cortes na Sessão Legislativa de 1874 pelo Ministro e Secretario D'Estado dos Negocios da Marinha e Ultramar. Lisboa: Imprensa Nacional, 1874.

ELIAS, Maria José. Introdução ao estudo da imigração chinesa. Anais do Museu Paulista, São Paulo, v. XXIV, pp. 55-100, 1970.

EMMER, Pieter C. European Expansion and Unfree Labour: An Introduction. Itinerario, Leiden, v. 21, n. 1, pp. 9-15, 1997.

GUIMARÃES, Isidoro Francisco. Cópia $\mathrm{N}^{\circ} 1$, anexa ao Ofício $\mathrm{N}^{\circ} 3$, de 12/01/1858, de Isidoro Francisco Guimarães, Governador de Macau; Cx. 24 - 1858, Macau - SEMU - DGU - 005 (Arquivo Histórico Ultramarino, AHU). 12 jan. 1858a.

GUIMARÃES, Isidoro Francisco. Cópia $\mathrm{N}^{\circ}$ 2, anexa ao Ofício $\mathrm{N}^{\circ} 3$, de 12/01/1858, de Isidoro Francisco Guimarães, Governador de Macau; Cx. 24 - 1858, Macau - SEMU - DGU - 005 (Arquivo Histórico Ultramarino, AHU). 12 jan. 1858b.

GUIMARÃES, Isidoro Francisco. Ofício $\mathrm{N}^{\circ} 3$, de 12/01/1858, de Isidoro Francisco Guimarães, Governador de Macau, Governador de Macau; Cx. 24 - 1858, Macau - SEMU - DGU - 005 (Arquivo Histórico Ultramarino, AHU). 12 jan. 1858c.

JERÓNIMO, Miguel Bandeira. Livros brancos, corpos e almas negras: a "missão civilizadora" do colonialismo português (c.1870-1930). Lisboa: ICS - Imprensa de Ciências Sociais, 2010.

NASCIMENTO, Augusto. A passagem de coolies por S. Tomé e Príncipe. Arquipélago - História, Ponta Delgada/Açores, 2a série, v. 8, pp. 77-111, 2004.

NORTHRUP, David. Indentured Labor in the Age of Imperialism, 1834-1922. Nova York: Cambridge University Press, 1995.

PEREIRA, António Feliciano Marques. Relatorio da emigração chineza em Macau, dirigido a S. Ex. o Governador Geral de Macau, Isidoro Francisco Guimarães. Macau: Typographia de J. da Silva, 1861.

PORTARIA DE 27/02/1857. Legislação Régia - Livro 1857. Disponível em: http://legislacaoregia.parlamento.pt/Pesquisa/Default.aspx?ts=1. Acesso em: 02 set. 2020. SCOTT, Rebecca J. Emancipação escrava em Cuba: a transição para o trabalho livre, 1860-1899. Rio de Janeiro: Paz e Terra; Campinas/SP: Editora da Unicamp, 1991. TAPPE, Oliver; LINDNER, Ulrike. Introduction: Global variants of bonded labour. In: DAMIR-GEILSDORF, Sabine et al. Bonded Labour: Global and comparative perspectives (18th-21st Century). Bielefeld: Transcript, 2016. pp. 9-34.

TOMICH, Dale W. Pelo prisma da escravidão: trabalho, capital e economia mundial. São Paulo: Edusp, 2012. 
WILLIAMS, Eric. Capitalismo e escravidão. Tradução e notas de Carlos Nayfeld. Rio de Janeiro: Editora Americana, 1975.

YOUNG, Elliott. Chinese Coolies, Universal Rights, and the Limits of Liberalism in an Age of Empire. Past \& Present, Oxford, v. 227, n. 1, pp. 121-149, 2015.

ZEUSKE, Michael. Coolies - Asiáticos and Chinos: Global Dimensions of Second Slavery. In: DAMIR-GEILSDORF, Sabine et al. Bonded Labour: Global and comparative perspectives (18th-21st Century). Bielefeld: Transcript, 2016. pp. 35-57.

ZEUSKE, Michael. Esclavitud: una historia de la humanidad. Pamplona: Katakrak, 2018.

\section{NOTAS}

${ }^{1}$ Pesquisa financiada pela Fundação de Amparo à Pesquisa do Estado de São Paulo (FAPESP), modalidade Auxílio à Pesquisa Regular (Processo n. 2018/00615-9).

${ }^{2}$ Sobre as origens orientais do termo coolie e a transformação do seu conceito, identificado com o trabalho sob contrato, ver Balachandran (2011).

${ }^{3} \mathrm{Na}$ documentação pesquisada não foi possível averiguar se isso realmente ocorreu.

Artigo submetido em 10 de novembro de 2020. Aprovado em 04 de maio de 2021. 